\title{
Oridonin exerts protective effects against hydrogen peroxide-induced damage by altering microRNA expression profiles in human dermal fibroblasts
}

\author{
EUN-JIN LEE ${ }^{1 *}$, HWA JUN CHA ${ }^{1,2^{*}}$, KYU JOONG AHN ${ }^{3}$, IN-SOOK AN ${ }^{2,4}$, \\ SUNGKWAN AN ${ }^{1,2,4}$ and SEUNGHEE BAE ${ }^{1,2}$
}

\author{
${ }^{1}$ Molecular-Targeted Drug Research Center and ${ }^{2}$ Korea Institute for Skin and Clinical Sciences, Konkuk University; \\ ${ }^{3}$ Department of Dermatology, Konkuk University School of Medicine; ${ }^{4}$ Department of Cosmetology, \\ Graduate School of Engineering, Konkuk University, Seoul 143-701, Republic of Korea
}

Received July 25, 2013; Accepted October 10, 2013

DOI: $10.3892 /$ ijmm.2013.1533

\begin{abstract}
The aim of the present study was to evaluate the protective effects of oridonin on hydrogen peroxide-induced cytotoxicity in normal human dermal fibroblasts (NHDFs) using microRNA (miRNA) expression profile analysis. Oridonin was not cytotoxic at low doses $(\leq 5 \mu \mathrm{M})$ in the NHDFs, and pre-treatment of the cells with oridonin significantly reduced hydrogen dioxide $\left(\mathrm{H}_{2} \mathrm{O}_{2}\right)$-mediated cytotoxicity and cell death. Whereas oridonin showed no free radical scavenging activity in in vitro and in vivo antioxidant assays, treatment of the NHDFs with oridonin was associated with intracellular scavenging of reactive oxygen species. High-density miRNA microarray analysis revealed alterations in the expression profiles of specific miRNAs (5 upregulated and 22 downregulated) following treatment with oridonin in the $\mathrm{H}_{2} \mathrm{O}_{2}$-treated NHDFs. Moreover, the use of a miRNA target-gene prediction tool and Gene Ontology analysis demonstrated that these miRNAs are functionally related to the inhibition of apoptosis and cell growth. These data provide valuable insight into the cellular responses to oridonin in $\mathrm{H}_{2} \mathrm{O}_{2}$-induced damage in NHDFs.
\end{abstract}

\section{Introduction}

Oxidative stress generated by reactive oxygen species (ROS) induces non-specific intracellular damage, such as DNA breaks, mitochondrial failure, protein oxidation and impairment of energy metabolism (1). These types of oxidative

Correspondence to: Dr Seunghee Bae, Molecular-Targeted Drug Research Center, Konkuk University, 120 Neungdong-ro, Hwayangdong, Gwangjin-gu, Seoul 143-701, Republic of Korea

E-mail:sbae@konkuk.ac.kr

*Contributed equally

Key words: oridonin, human dermal fibroblast, hydrogen peroxide, microRNA, cell viability damage lead to cell cycle arrest, and induce senescence and apoptosis (1). Therefore, the impairment of antioxidant defenses can cause cell aging and death, as well as certain diseases, including cardiovascular, neurodegenerative and dermatological diseases (2-4). Human dermal fibroblasts (HDFs) are the most abundant cells in the dermis of the skin, which is the largest organ in the human body. In this position, HDFs are more vulnerable than other cells to toxic environmental agents, particularly ultraviolet radiation, which generates a high level of oxidative stress. Therefore, ROS-mediated oxidative stress has been the primary therapeutic target to prevent stress-mediated dermatological diseases. There are several antioxidant chemicals and the cellular mechanisms underlying their actions have been investigated. Oat bran extracts exert a protective effect against HDF damage induced by hydrogen peroxide $\left(\mathrm{H}_{2} \mathrm{O}_{2}\right)(5)$. The terpenoids, resveratrol and curcumin, also have antioxidant properties as a result of their free radical-scavenging activity and regulation of cellular signaling pathways. Resveratrol activates AMP-activated kinase (AMPK) to induce an antioxidant effect $(6,7)$. Curcuminoids regulate the Smac/DIABLO, p53, NF- $\kappa$ B and MAPK pathways for their antioxidant effects (8). Furthermore, a number of studies have demonstrated that $\mathrm{H}_{2} \mathrm{O}_{2}$, which has been extensively used as a ROS inducer, can regulate transcription by altering gene expression profiles (9-11). Analysis of the intracellular mechanisms underlying antioxidative effects has primarily focused on protein-based signaling pathways and gene expression profiles; however, it largely remains to be determined whether small-RNA-based mechanisms can affect antioxidant activity in HDFs.

Oridonin, a terpenoid purified from Rabdosia rubescens, has various pharmacological and biological effects, including anti-inflammatory, antibacterial and anticancer effects (12). Recently, considerable attention has been paid to the anticancer activity of oridonin. Indeed, oridonin can induce cell cycle arrest, defects in migration and invasion and apoptosis in a variety of cancer cells (13-16). Oridonin also generates high levels of ROS, ultimately triggering apoptosis in cancer cells (17-19). By contrast, normal cells are less sensitive to oridonin-mediated cytotoxicity. Chen et al (20) demonstrated 
that, at concentrations that induce apoptosis in tumor cells, oridonin failed to induce apoptosis in cultures of normal human CCD-18Co fibroblasts. Also, Du et al (21) demonstrated that oridonin protects from sodium arsenite [As(III)]-induced cytotoxicity by reducing ROS levels in the human UROtsa urothelium cell line. Furthermore, the authors suggested that oridonin at low doses functions as a chemopreventive compound from As(III)-mediated oxidative stress, whereas at high doses, it functions as a pro-apoptotic agent (21). However, how oridonin affects antioxidative stress activity in cells remains largely unknown.

microRNAs (miRNAs), which are non-coding RNAs, function as post-transcriptional regulators by direct interaction with target mRNAs, and inhibit target protein expression (22). Several miRNA-based studies have been carried out using HDFs. An et al (23) reported that miRNA expression profiles were altered by Centella asiatica, which exerts a UVB-protective effect on normal HDFs (NHDFs). Mancini et al (24) demonstrated that miR-152 and miR-181a induce HDF senescence, and Sing et al (25) showed that the expression levels of miR-92 in HDFs increased in patients with scleroderma. Although an increasing number of functional studies on miRNAs has been carried out using HDFs, it is unknown which miRNAs are involved in the antioxidant activity in these cells. In the present study, we demonstrated that oridonin acts as a bona fide antioxidant compound in NHDFs and we characterized the specific changes in miRNA expression that correspond to oridonin-mediated protection from $\mathrm{H}_{2} \mathrm{O}_{2}$-induced cytotoxicity.

\section{Materials and methods}

Cell culture and reagents. The NHDF cell line was obtained from Lonza (Basel, Switzerland) and cultured in Gibco ${ }^{\circledR}$ Dulbecco's modified Eagle's medium (DMEM; Invitrogen, Carlsbad, CA, USA) supplemented with $10 \%$ fetal bovine serum (FBS; Sigma-Aldrich, St. Louis, MO, USA) and penicillin/streptomycin in a humidified atmosphere of $95 \%$ air $/ 5 \% \mathrm{CO}_{2}$ at $37^{\circ} \mathrm{C}$. The NHDFs were seeded in 96-well plates $\left(4 \times 10^{3}\right.$ cells/well) for the water-soluble tetrazolium salt (WST-1) assay, and in 60-mm dishes (7x10 5 cells/dish) for flow cytometry-based assay and RNA purification. Oridonin was purchased from Sigma-Aldrich, and $\mathrm{H}_{2} \mathrm{O}_{2}(30 \%)$ was purchased from Merck KGaA (Darmstadt, Germany). Oridonin was dissolved in dimethyl sulfoxide (DMSO; Sigma-Aldrich), and $\mathrm{H}_{2} \mathrm{O}_{2}$ was diluted with deionized water.

WST-1 assay. WST-1 assay was carried out to analyze cell viability (26). The NHDFs were seeded in 96-well plates $\left(4 \times 10^{3}\right.$ cells/well). The day after seeding, the cells were treated with various concentrations of oridonin for $24 \mathrm{~h}$. Cell viability was assessed following incubation with WST-1 solution (EZ-Cytox Cell Viability Assay kit; Itsbio, Seoul, Korea) at $37^{\circ} \mathrm{C}$ for $1 \mathrm{~h}$. Formazan dye formation was evaluated using a scanning multiwall spectrophotometer (iMark microplate reader; Bio-Rad, Hercules, CA, USA) at $450 \mathrm{~nm}$ and a $620-\mathrm{nm}$ reference filter. The results are expressed as optical density (OD) units or the percentage viability relative to the control. To assess the protective effects of oridonin against $\mathrm{H}_{2} \mathrm{O}_{2}$-induced damage, the cells were pre-treated with the control (DMSO; Sigma-
Aldrich) or oridonin for $3 \mathrm{~h}$, and then treated with $800 \mu \mathrm{M} \mathrm{H}_{2} \mathrm{O}_{2}$ for $5 \mathrm{~h}$. At the end of $\mathrm{H}_{2} \mathrm{O}_{2}$ stimulation, the cells were analyzed by WST-1 assay. The results are presented as the means \pm SD of 3 independent experiments. The Student's t-test was used for a comparison of the means.

Propidium iodide (PI) assay. PI assay was used for flow cytometric analysis of cell death, as previously described (27). NHDFs $\left(7 \times 10^{5}\right)$ were pre-treated with oridonin for $3 \mathrm{~h}$, followed by incubation in the presence or absence of $800 \mu \mathrm{M} \mathrm{H}_{2} \mathrm{O}_{2}$ for $3 \mathrm{~h}$. The cells were collected and incubated in staining solution containing $50 \mu \mathrm{g} / \mathrm{ml}$ PI, $0.5 \%$ Triton X-100 (both from Sigma-Aldrich), and $100 \mu \mathrm{g} / \mathrm{ml}$ RNase at $37^{\circ} \mathrm{C}$ for $1 \mathrm{~h}$. The level of cell death was determined by evaluating the intensity of fluorescent PI staining using the FL2-H channel of a FACSCalibur (BD Biosciences, San Jose, CA, USA).

2'7'-Dichlorofluorescein diacetate (DCF-DA) assay. Levels of intracellular ROS were determined by DCF-DA assay, as previously described (28). Briefly, NHDFs $\left(7 \times 10^{5}\right)$ were seeded in growth medium in 60-mm culture dishes. Twenty-four hours later, cells were pretreated with oridonin for $3 \mathrm{~h}$, and then with $800 \mu \mathrm{M} \mathrm{H}_{2} \mathrm{O}_{2}$ for $3 \mathrm{~h}$. Following $\mathrm{H}_{2} \mathrm{O}_{2}$ treatment, cells were washed with phosphate-buffered saline (PBS) and trypsinized. Cells were resuspended and stained with $20 \mu \mathrm{M}$ DCF-DA (Sigma-Aldrich) in PBS at room temperature for $1 \mathrm{~h}$. Fluorescence was measured using a flow cytometer (BD FACSCalibur; BD Biosciences). The mean of DCF fluorescence intensity was calculated based on measurements of 10,000 cells using the FL1-H channel. M1 range (Fig. 3) indicates the percentage of each subpopulation of cells with increased DCF-DA fluorescence.

RNA preparation and assessment of quality. Total RNA, including mRNAs, small RNAs and miRNAs, was extracted from each group of NHDFs using TRIzol reagent (Invitrogen) according to the manufacturer's protocol. RNA integrity was confirmed using an Agilent 2100 Bioanalyzer ${ }^{\circledR}$ (Agilent Technologies, Santa Clara, CA, USA). The purity (A260/A280 and A260/A230 ratios) and concentration of RNA samples were determined using a MaestroNano ${ }^{\circledR}$ microvolume spectrophotometer (Maestrogen, Las Vegas, NV, USA).

miRNA expression profile analysis. miRNA expression profiling of NHDFs was conducted using SurePrint G3 Human v16 miRNA $8 \times 60 \mathrm{~K}$ microarrays (Agilent Technologies), containing probes for 1,205 human miRNAs, according to the manufacturer's protocol. Briefly, total RNA (100 ng) was 3'-dephosphorylated using calf intestine alkaline phosphatase (CIP) prior to labeling with cyanine 3-pCp using T4 RNA ligase. After the labeling procedure, the RNA samples were dried and diluted with GE Blocking Agent (Agilent Technologies), hybridized to the probes on the microarray in the Agilent Microarray Hybridization Chamber (Agilent Technologies) for $20 \mathrm{~h}$, and then washed three times. The fluorescence intensities of the labeled miRNA samples bound to microarrays were measured using the Agilent Microarray Scanner. Numerical data for the miRNA profiles were extracted from the image using the Feature Extraction program (Agilent Technologies). These data were analyzed using GeneSpring 
A

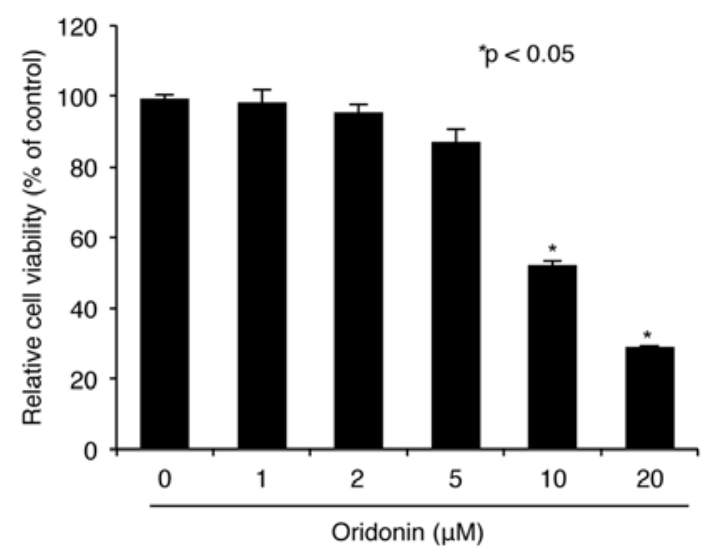

B

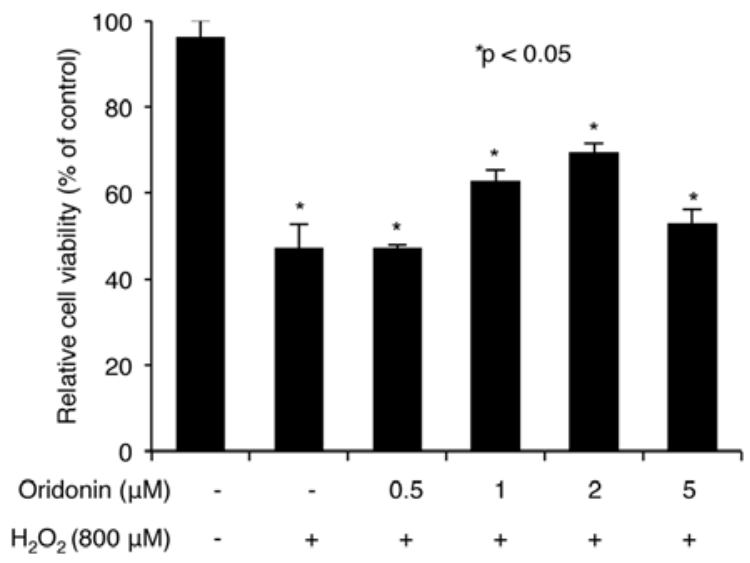

Figure 1. Hydrogen dioxide $\left(\mathrm{H}_{2} \mathrm{O}_{2}\right)$-mediated cytotoxicity in normal human dermal fibroblasts (NHDFs) was reduced by oridonin treatment. (A) Cytotoxicity of oridonin in NHDFs. NHDFs were seeded in 96-well plates and treated with the indicated concentrations of oridonin for 24 h. Cytotoxicity was measured by the WST-1 assay. Values are the means \pm SD. Results are representative of 3 independent experiments. The Student's t-test was performed to determine statistical significance. (B) Protective effects of oridonin treatment against $\mathrm{H}_{2} \mathrm{O}_{2}$-induced damage in NHDFs. Cells were treated with control dimethyl sulfoxide (DMSO) or oridonin for $3 \mathrm{~h}$, and then with $\mathrm{H}_{2} \mathrm{O}_{2}$. After further incubation for $24 \mathrm{~h}$, cell viability was determined using the WST-1 assay. Values are the means \pm SD. Results are representative of 3 independent experiments. The Student's t-test was performed to determine statistical significance.

GX software version 11.5 (Agilent Technologies). miRNAs for which flags were present in at least one sample were filtered and applied to the fold-change analysis. The fold-change analysis was conducted based on a factor of 1.5-fold between two groups, $\mathrm{H}_{2} \mathrm{O}_{2}$-treated control cells and cells treated with oridonin and $\mathrm{H}_{2} \mathrm{O}_{2}$.

Bioinformatic analysis of miRNAs. To assess the biological significance of the changes in miRNA expression, 3 bioinformatic analyses were performed: prediction of the putative target genes of the miRNAs, grouping of target genes with similar biological functions, and additional subgrouping of the target genes with more specific biological functions. The putative miRNA target genes were determined using MicroCosm Targets version 5 (http://www.ebi.ac.uk/enright-srv/microcosm/htdocs/targets/v5/). Target genes were categorized into 4 groups: aging, apoptosis, cell proliferation and skin development using the AmiGO Gene Ontology (GO) analysis tool (amigo.geneontology.org/cgi-bin/amigo/browse.cgi). Further GO analysis was performed in several categories, i.e., antiapoptosis, activation of MAPKK activity, Ras protein signal transduction, small GTPase-mediated signal transduction, positive or negative regulation of cell growth, cell proliferation, cell cycle, antioxidant and positive regulation of DNA repair.

\section{Results}

Oridonin exerts a protective effect against $\mathrm{H}_{2} \mathrm{O}_{2}$-induced damage in NHDFs. Previously, ROS was considered a main activator of oridonin-mediated cytotoxicity in cancer cell lines (17-19). However, other studies have indicated that oridonin does not induce cell death, but protects cells from As(III)-induced ROS damage in the human UROtsa urothelium cell line (20,21). Moreover, oridonin does not induce cell death in cultures of normal human fibroblasts (20). Therefore, we sought to determine whether oridonin is indeed able to protect normal human cells against ROS-induced stress.
Utilizing a NHDF line, we first determined the cytotoxic and antioxidant effects of oridonin using a WST-1 based cell viability assay. We treated the NHDFs with various doses of oridonin for $24 \mathrm{~h}$ and found that ordonin-induced cytotoxicity was concentration-dependent (Fig. 1A). Although oridonin was cytotoxic at relatively high concentrations of 10 and $20 \mu \mathrm{M}$, low doses of $\sim 5 \mu \mathrm{M}$ had little cytotoxic effects (Fig. 1A). Also, relatively high doses $(\sim 1 \mathrm{mM})$ of $\mathrm{H}_{2} \mathrm{O}_{2}$, which have been extensively used to induce ROS, induced the loss of cell viability in NHDFs (data not shown). $\mathrm{H}_{2} \mathrm{O}_{2}$ at a dose of $1 \mathrm{mM}$ showed extremely high cytotoxicity; therefore, we used $800 \mu \mathrm{M} \mathrm{H}_{2} \mathrm{O}_{2}$ for further experiments.

Subsequently, to demonstrate that oridonin exerts a protective effect against $\mathrm{H}_{2} \mathrm{O}_{2}$-mediated cell damage, we performed sequential-treatment-based cell viability analysis using NHDFs pre-treated with oridonin and post-treated with $\mathrm{H}_{2} \mathrm{O}_{2}$ (Fig. 1B). The results revealed that pre-treatment with low doses (1 and $2 \mu \mathrm{M}$ ) of oridonin prior to exposure to $\mathrm{H}_{2} \mathrm{O}_{2}$ markedly reduced the cytotoxicity of $\mathrm{H}_{2} \mathrm{O}_{2}$ in NHDFs (Fig. 1B). Although treatment with $5 \mu \mathrm{M}$ oridonin did not protect against the $\mathrm{H}_{2} \mathrm{O}_{2}$-mediated loss of cell viability, this result was attributed to the cytotoxic effects of $5 \mu \mathrm{M}$ oridonin on NHDFs. Taken together, these data suggest that low doses of oridonin enhance the tolerance to $\mathrm{H}_{2} \mathrm{O}_{2}$-induced growth defects in NHDFs.

Low-dose oridonin reduces $\mathrm{H}_{2} \mathrm{O}_{2}$-mediated cell death. Stimulation of cells with high levels of $\mathrm{H}_{2} \mathrm{O}_{2}$ has been linked to cell cycle arrest and cell death (1). In order to determine whether oridonin affects $\mathrm{H}_{2} \mathrm{O}_{2}$-mediated cell cycle arrest and cell death, we stained control, $\mathrm{H}_{2} \mathrm{O}_{2}$ - or oridonin-treated, and oridonin-pre-treated $/ \mathrm{H}_{2} \mathrm{O}_{2}$-treated cells with the fluorescent dye, PI, and investigated cellular DNA content by flow cytometry to analyze the cell cycle pattern. Low-dose $(2 \mu \mathrm{M})$ oridonin treatment did not induce cell cycle arrest compared with the control (Fig. 2A and B). However, treatment with $\mathrm{H}_{2} \mathrm{O}_{2}(800 \mu \mathrm{M})$ increased the percentage of cells in the sub-G1 phase from $2.12 \%$ in the control cells to $11.49 \%$ in the 
A

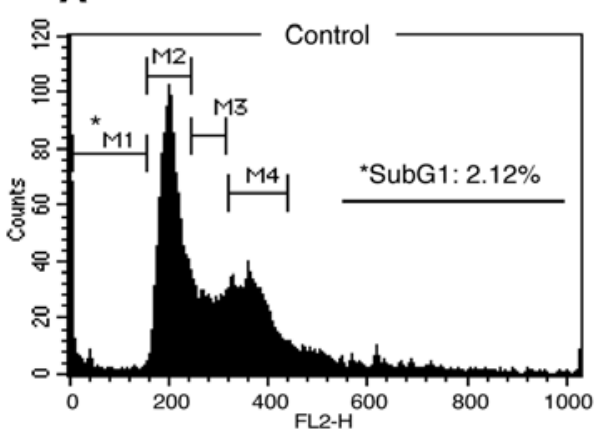

C

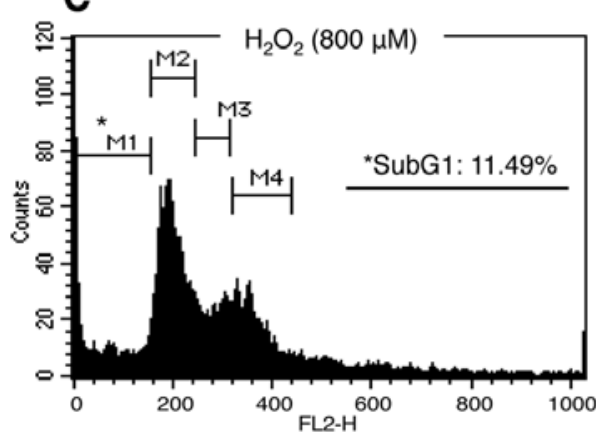

B
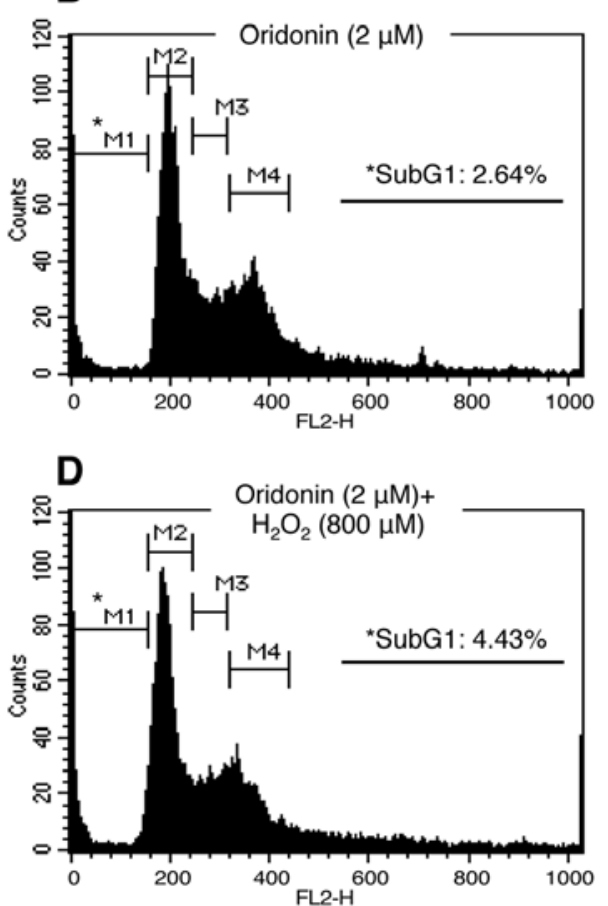

Figure 2. Hydrogen dioxide $\left(\mathrm{H}_{2} \mathrm{O}_{2}\right)$-mediated normal human dermal fibroblast (NHDF) death was reduced by oridonin treatment. NHDFs were seeded on $60-\mathrm{mm}$ plates, treated with dimethyl sulfoxide (DMSO) or oridonin for $3 \mathrm{~h}$, and then treated with $\mathrm{H}_{2} \mathrm{O}_{2}$. Following further incubation for $24 \mathrm{~h}$, cells were collected and stained with PI for $1 \mathrm{~h}$, and cell death was measured by flow cytometry. (A) Control, (B) oridonin-treated, (C) $\mathrm{H}_{2} \mathrm{O}_{2}$-treated and (D) oridoninpre-treated and $\mathrm{H}_{2} \mathrm{O}_{2}$ - treated cells.

A

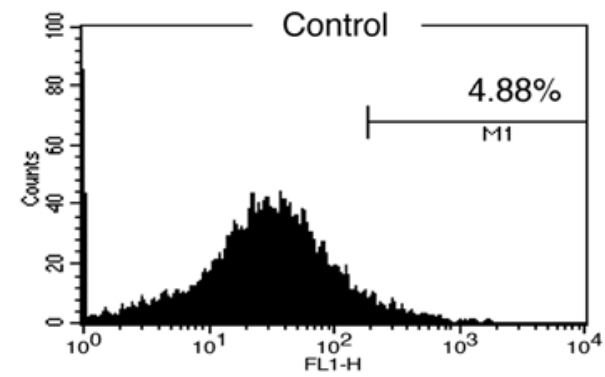

C

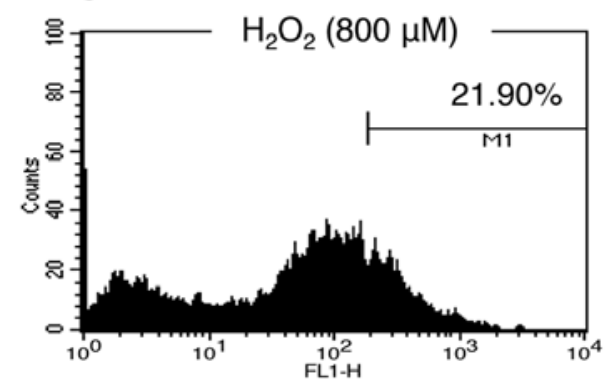

B

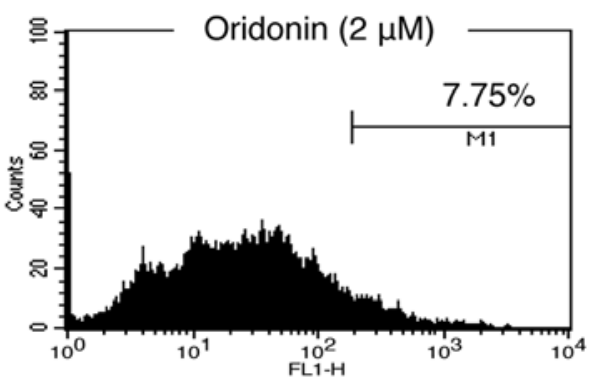

D Oridonin $(2 \mu \mathrm{M})+$

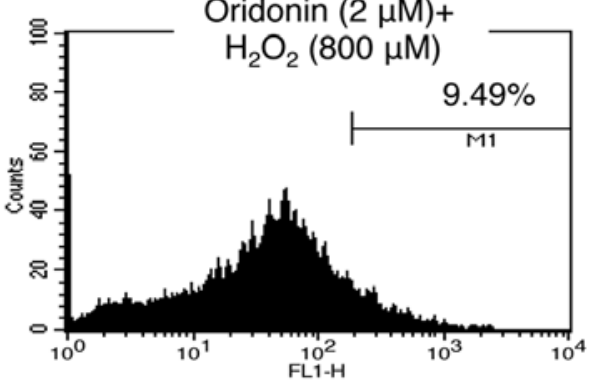

Figure 3. Hydrogen dioxide $\left(\mathrm{H}_{2} \mathrm{O}_{2}\right)$-mediated ROS induction was reduced by oridonin treatment. Normal human dermal fibroblasts (NHDFs) were pre-treated with dimethyl sulfoxide (DMSO) or oridonin for $3 \mathrm{~h}$, followed by $\mathrm{H}_{2} \mathrm{O}_{2}$ treatment and further incubation for $3 \mathrm{~h}$. Cells were collected and stained with DCF-DA solution for $1 \mathrm{~h}$. Levels of intracellular ROS were measured by flow cytometry. (A) Control, (B) oridonin-treated, (C) $\mathrm{H}_{2} \mathrm{O}_{2}$-treated and (D) oridonin-pre-treated and $\mathrm{H}_{2} \mathrm{O}_{2}$-treated cells.

$\mathrm{H}_{2} \mathrm{O}_{2}$-treated cells (Fig. 2C). Furthermore, pre-treatment with oridonin markedly diminished the rate of $\mathrm{H}_{2} \mathrm{O}_{2}$-mediated cell death from $11.49 \%$ in the $\mathrm{H}_{2} \mathrm{O}_{2}$-treated cells to $4.43 \%$ in the oridonin-pre-treated $\mathrm{H}_{2} \mathrm{O}_{2}$-treated cells (Fig. 2D). These data suggest that oridonin functions as an anti-cell-death agent in $\mathrm{H}_{2} \mathrm{O}_{2}$-induced cell damage in NHDFs. 

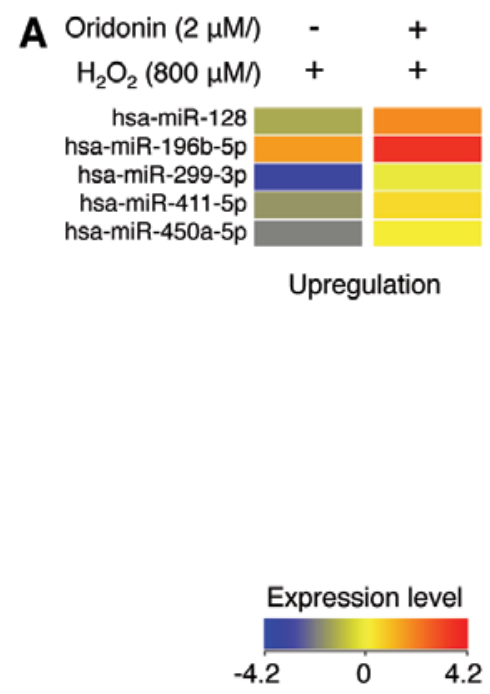

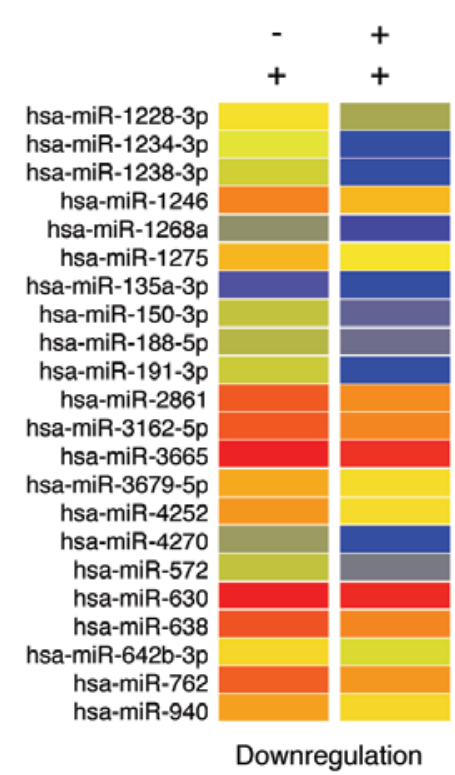

B

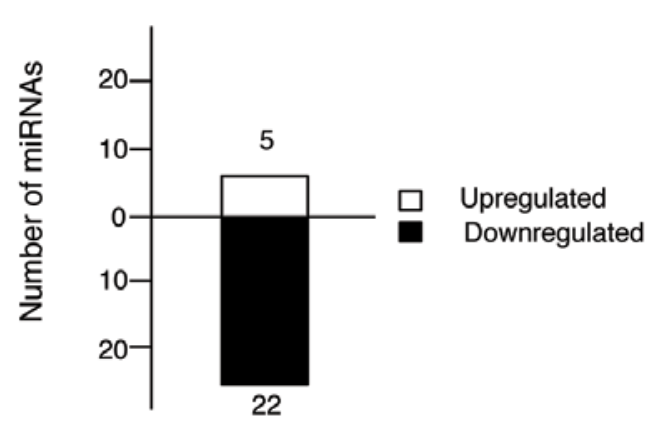

Figure 4. Oridonin alters microRNA (miRNA) expression profiles. (A) Expression profiles of specific miRNAs were altered following oridonin treatment in hydrogen dioxide $\left(\mathrm{H}_{2} \mathrm{O}_{2}\right)$-treated normal human dermal fibroblasts ( $\left.\mathrm{NHDFs}\right)$. NHDFs were treated with oridonin and then with $\mathrm{H}_{2} \mathrm{O}_{2}$. miRNA microarrays were performed to identify changes in miRNA expression profiles. miRNAs upregulated (left panel) and downregulated (right panel) by oridonin treatment and their expression levels in $\mathrm{H}_{2} \mathrm{O}_{2}$-treated NHDFs are shown in schematic heat maps. (B) Graph shows the number of miRNAs up- and downregulated by oridonin treatment of $\mathrm{H}_{2} \mathrm{O}_{2}$-treated NHDFs.

Low-dose oridonin exerts an antioxidant effect. Since $\mathrm{H}_{2} \mathrm{O}_{2}$ mediated cell death was inhibited by pre-treatment with low-dose oridonin (Figs. 1 and 2), we sought to determine whether oridonin also functions as a bona fide antioxidant agent. To examine the possibility that oridonin has free radical-scavenging activity, we employed 2 types of assay, a cell-free DPPH assay and a cell-based DCF-DA assay. First, we measured the free radical-scavenging effects of oridonin using the DPPH assay and observed that oridonin alone did not reduce free radical DPPH in vitro (data not shown). To investigate the antioxidant activity of oridonin in vivo, we measured intracellular ROS levels using DCF-DA staining and flow cytometry. Intracellular levels of ROS were not increased in the oridonin-treated NHDFs (Fig. 3A and B), but were increased to $21.90 \%$ in the $\mathrm{H}_{2} \mathrm{O}_{2}$-treated NHDFs (Fig. 3C). Of note, the high levels of ROS in the $\mathrm{H}_{2} \mathrm{O}_{2}$-treated cells were markedly reduced to $9.49 \%$ in the oridonin-pre-treated $\mathrm{H}_{2} \mathrm{O}_{2}$-treated NHDFs (Fig. 3D). Therefore, although oridonin alone exerts no free radical-scavenging effect, it clearly demonstrates intracellular ROS-scavenging activity in NHDFs. Taken together, these data suggest that the oridonin-mediated protective effects against $\mathrm{H}_{2} \mathrm{O}_{2}$ damage are induced by the regulation of intracellular ROS scavenging mechanisms, rather than resulting from the free radical-scavenging activity of oridonin alone.

Protective role of oridonin in $\mathrm{H}_{2} \mathrm{O}_{2}$-induced NHDF damage is reflected in changes in miRNA expression profiles. Oridonin affected the levels of $\mathrm{H}_{2} \mathrm{O}_{2}$-mediated cell death by regulating intracellular ROS generation, rather than free radical scavenging of oridonin alone. Therefore, we investigated the cellular mechanisms underlying the oridonin-mediated protective effects against $\mathrm{H}_{2} \mathrm{O}_{2}$-induced damage. Since various miRNAs regulate cell proliferation, apoptosis, development and differentiation, we aimed to identify the miRNAs related to the oridonin-mediated protective effects. We used a highdensity microarray of 1,205 miRNAs to search for differences in miRNA expression associated with the oridonin-mediated protective effects in this system. Purified total RNA was labeled with the fluorescent dye, cyanine 3-pCp, and hybridized to the samples on the microRNA microarray. Using the bioinformatics software GeneSpring GX version 7.3, miRNAs showing $\geq 1.5$-fold change in expression and with a $p$-value of $\leq 0.05$ were selected (Fig. 4 and Table I). We found that 5 miRNAs were upregulated and 22 miRNAs were downregulated under the experimental conditions. Notably, miR-1238-3p and $\mathrm{miR}-191-3 \mathrm{p}$ were significantly downregulated by 7.40 - and 7.01-fold, respectively, whereas the expression of miR-128 was significantly increased by 2.01 -fold. These data suggest that oridonin affects the expression levels of specific miRNAs in response to $\mathrm{H}_{2} \mathrm{O}_{2}$-mediated cell damage in NHDFs.

Bioinformatic analysis of oridonin-specific miRNAs and their putative targets. The biological functions of miRNAs are dependent on those of their target genes, whose expression is post-transcriptionally regulated by specific miRNAs (29). Having determined that specific miRNAs are regulated by oridonin, we investigated the biological significance of the changes in miRNA expression in the oridonin-mediated protective effects against $\mathrm{H}_{2} \mathrm{O}_{2}$ in NHDFs. We considered 3 criteria: the putative target genes, biological functions of the target genes and the mechanisms underlying the functions of the target genes. We first analyzed the putative target genes of the miRNAs of interest using the bioinformatics tool miRBase Target Database tool (Microcosm). We then categorized the putative target genes into 4 types according to biological function, i.e., aging, cell proliferation, apoptosis and skin 
Table I. miRNA whose expression was altered in response to oridonin in $\mathrm{H}_{2} \mathrm{O}_{2}$-treated NHDFs.

\begin{tabular}{|c|c|c|c|c|c|}
\hline $\operatorname{miRNA}^{\mathrm{a}}$ & $\mathrm{FC}$ & Chromosome & miRNA & $\mathrm{FC}$ & Chromosome \\
\hline hsa-miR-1228-3p & -1.97 & Chr12 & hsa-miR-4252 & -1.90 & Chr1 \\
\hline hsa-miR-1234-3p & -4.22 & Chr8 & hsa-miR-4270 & -2.61 & Chr3 \\
\hline hsa-miR-1238-3p & -7.40 & Chr19 & hsa-miR-572 & -1.55 & Chr4 \\
\hline hsa-miR-1246 & -1.63 & Chr2 & hsa-miR-630 & -1.56 & Chr15 \\
\hline hsa-miR-1268a & -1.55 & Chr15 & hsa-miR-638 & -1.68 & Chr19 \\
\hline hsa-miR-1275 & -1.53 & Chr6 & hsa-miR-642b-3p & -1.59 & Chr19 \\
\hline hsa-miR-135a-3p & -2.63 & Chr3 & hsa-miR-762 & -1.73 & Chr16 \\
\hline hsa-miR-150-3p & -1.76 & Chr19 & hsa-miR-940 & -1.63 & Chr16 \\
\hline hsa-miR-188-5p & -1.53 & ChrX & hsa-miR-128 & 2.01 & Chr2 \\
\hline hsa-miR-191-3p & -7.01 & Chr3 & hsa-miR-196b-5p & 1.65 & Chr7 \\
\hline hsa-miR-2861 & -1.67 & Chr9 & hsa-miR-299-3p & 1.90 & Chr14 \\
\hline hsa-miR-3162-5p & -1.59 & Chr11 & hsa-miR-411-5p & 1.57 & Chr14 \\
\hline hsa-miR-3665 & -1.62 & Chr13 & hsa-miR-450a-5p & 1.57 & ChrX \\
\hline hsa-miR-3679-5p & -1.90 & Chr2 & & & \\
\hline
\end{tabular}

NHDFs, normal human dermal fibroblasts. ${ }^{a}$ miRNAs showing $>1.5$-fold change in expression after flag sorting. FC, fold change; miRNAs, microRNAs; $\mathrm{H}_{2} \mathrm{O}_{2}$, hydrogen dioxide.

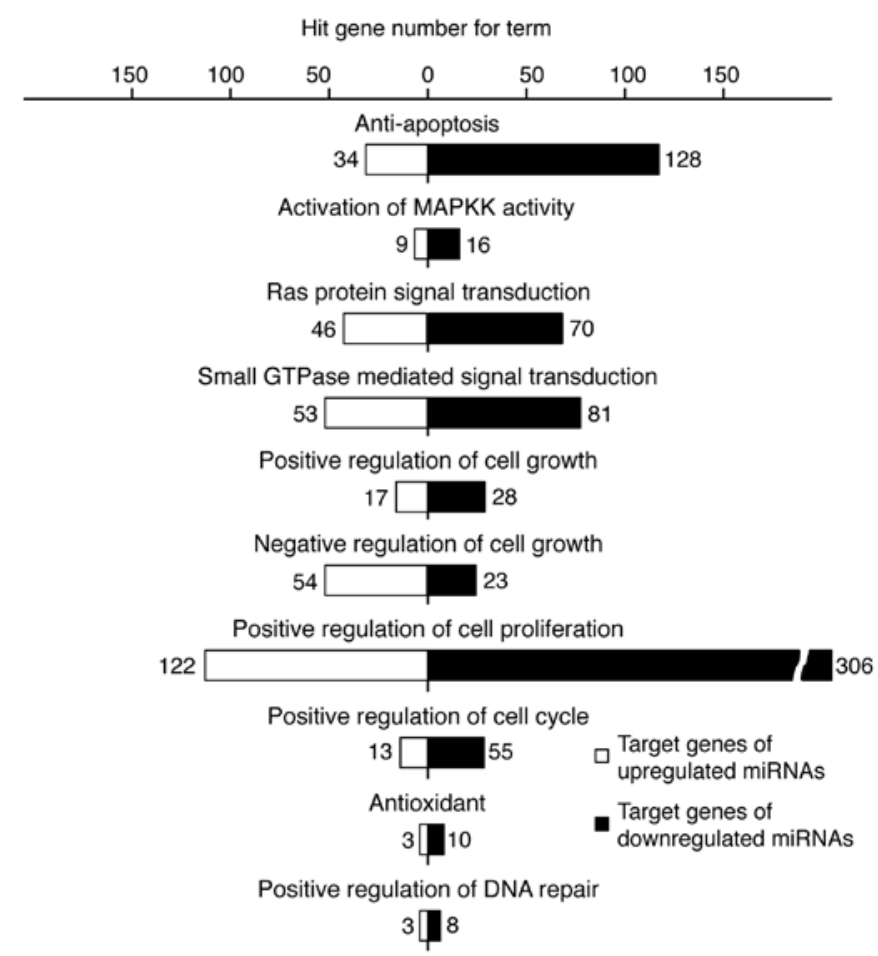

Figure 5. Analysis of subcategories of biological functions of the microRNA (miRNA) target genes. The target genes of the altered miRNAs were grouped into the indicated biological functions using the bioinformatics tool AmiGO.

development (Tables II and III). A single miRNA may target a number of mRNAs and, conversely, a single mRNA target may be modulated by several miRNAs. Since treatment with $\mathrm{H}_{2} \mathrm{O}_{2}$ induced aging and apoptosis in several cell types, including cancer cells and normal fibroblasts, these results suggest that the effects of oridonin may be functionally related to $\mathrm{H}_{2} \mathrm{O}_{2}$ properties by affecting the protein products of those genes. For example, putative target genes of miR-1238-3p, whose expression decreased by 7.40 -fold following treatment with oridonin, include structural maintenance of chromosome 6 (SMC6), insulin receptor substrate 1 (IRS1) and the alpha 2 chain of type V collagen (COL5A2). Conversely, miR-128 expression was decreased by 2.01 -fold following treatment with oridonin, and putative target genes include the tumor suppressor protein, p53 (TP53), BH3 interacting domain death agonist (BID) and forkhead box O1 (FOXO1).

The 4 basic biological functions described above can be subdivided into several intracellular signaling pathways. For example, apoptosis can include anti- and pro-apoptotic pathways, MAPK-mediated signal transduction and even a DNA-repair pathway (30). Therefore, we analyzed the categorization in greater detail and focused on pathways that are functionally related to $\mathrm{H}_{2} \mathrm{O}_{2}$-mediated cell damage, including the anti-apoptotic, positive- and negative-regulation of cell growth and proliferation, antioxidant and Ras- and small GTPase-mediated signal transduction pathways (1). As illustrated in Fig. 5, the target genes of the upregulated miRNAs are involved in promoting processes associated with cell proliferation; however, those of the downregulated miRNAs are involved in promoting processes associated with cell proliferation and inhibiting processes associated with apoptosis. Collectively, these results suggest that the oridoninmediated protective effects against $\mathrm{H}_{2} \mathrm{O}_{2}$-induced damage in NHDFs are related to the changes in the expression of specific miRNAs involved in cell proliferation and apoptosis.

\section{Discussion}

Accumulating evidence suggests that oridonin is a non-cytotoxic agent in normal, but not cancer, cells. Previous studies have reported that oridonin exerts no cytotoxic effect on normal cells, but exerts a protective effect against arsenic-induced 
Table II. Predicted targets of miRNAs upregulated in response to oridonin in $\mathrm{H}_{2} \mathrm{O}_{2}$-treated NHDFs.

\begin{tabular}{|c|c|c|c|c|}
\hline \multirow[b]{2}{*}{ miRNA } & \multicolumn{4}{|c|}{ Target genes and functions } \\
\hline & Aging & Apoptosis & Cell proliferation & $\begin{array}{c}\text { Skin } \\
\text { development }\end{array}$ \\
\hline hsa-miR-128 & $\begin{array}{l}\text { CDKN2A, SIRT1, } \\
\text { TP53, MAPK14, } \\
\text { GRB2, ID2, } \\
\text { ADH5, FAS, } \\
\text { HMGA2, CDK6 }\end{array}$ & $\begin{array}{l}\text { CDKN2A, SIRT1, TP53, FAS, } \\
\text { PPARG, USP28, BMI, NOD1, } \\
\text { ATP7A, MCL1, BAX, TRAF1, } \\
\text { MAPK14, NGFR, TFAP2A, EGR3, } \\
\text { XIAP, BID, CASP8, MAPK3, } \\
\text { NKX3-1, EGFR, YAP1, PIK3RI, } \\
\text { HMGA2, GATA6, TCF7L2, } \\
\text { CYLD, FOXO1 }\end{array}$ & $\begin{array}{l}\text { CDKN2A, SIRT1, TP53, ID2, } \\
\text { NGFR, TFAP2A, EGR3, XIAP, } \\
\text { NKX3-1, PPARG, USP28, BID, } \\
\text { BMI1, JAG1, FRAP1, IRS1, } \\
\text { FOXO4, APPL2, BNC1, NR2F2, } \\
\text { TSC1, EGFR, TCF7L2, YAP1, } \\
\text { PIK3RI, SMAD2, FAS, } \\
\text { HMGA2, GATA6 }\end{array}$ & $\begin{array}{l}\text { NGFR, } \\
\text { TFAP2A, } \\
\text { ATP7A, } \\
\text { COL5A1, } \\
\text { PKD1, } \\
\text { COL3A1 }\end{array}$ \\
\hline hsa-miR-299-3p & $\begin{array}{l}\text { CTNNA1, EDN1, } \\
\text { IL1B, DDIT3, } \\
\text { TERT, ICAM1, } \\
\text { TIMP3, ADH4, } \\
\text { PRELP }\end{array}$ & $\begin{array}{l}\text { CTNNA1, EDN1, TERT, IL1B, } \\
\text { CDH13, DDIT3, CD28, CUL1, } \\
\text { DICER1, HDAC2, ADD1, BCL3, } \\
\text { VEGFA, AKAP13, MADD, SART1, } \\
\text { TCF7L2, YAP1, PIK3RI, } \\
\text { CYLD, ELMO2 }\end{array}$ & $\begin{array}{l}\text { CTNNA1, EDN1, IL1B, } \\
\text { CUL1, CDH13, DICER1, HDAC2, } \\
\text { VEFGA, CD28, ABI1, CDKN1C, } \\
\text { EGR1, ERF, IGF2, RAG2, } \\
\text { TGIF1, CD47, TCF7L2, YAP1, } \\
\text { PIK3RI, SMAD2, FOXN1 }\end{array}$ & $\begin{array}{l}\text { EDA, } \\
\text { FRAS1, } \\
\text { TCF7L2 }\end{array}$ \\
\hline hsa-miR-196b-5p & $\begin{array}{l}\text { SERPINE1, } \\
\text { HMGA1, FAS, } \\
\text { HMGA2, P2RY1 }\end{array}$ & $\begin{array}{l}\text { SERPINE1, CDKN1B, AHR, IL2, } \\
\text { PAK1, MAPK1, BIRC6, HMGA2, } \\
\text { GATA6, MAP3K1, PTK2, TOX3, } \\
\text { SMAD6, FAS, ROCK1, RASSF5, } \\
\text { FOXO1, ELMO2 }\end{array}$ & $\begin{array}{l}\text { SERPINE1, HMGA1, FAS, } \\
\text { CDKN1B, AHR, IL2, PAK1, } \\
\text { MAPK1, BIRC6, PDGFA, } \\
\text { CCR2, CYP1A1, ISG20, NRAS, } \\
\text { BCAT1, CASK, HMGA2, } \\
\text { GATA6, FOXN1 }\end{array}$ & $\begin{array}{l}\text { PDGFA, } \\
\text { COL1A2, } \\
\text { COL3A1 }\end{array}$ \\
\hline hsa-miR-411-5p & $\begin{array}{l}\text { ATM, PTEN, } \\
\text { CCL5, CASP2, } \\
\text { MAP2K1, CDK6 }\end{array}$ & $\begin{array}{l}\text { ATM, PTEN, CCL5, CASP2, } \\
\text { IL18, TCF7, CUL3, WANT7B, } \\
\text { PDCD7, NME6, DUSP1, IL19, } \\
\text { TOPORS, ERBB4, ANGPT1, RHOB, } \\
\text { PSMD5, FAM129B, MAP3K1, CYLD, } \\
\text { TIMM50, BCL2L14, CASP6, FOXO1 } \\
\text { LEF1, BCL11B, TFAP2B, ATG5, } \\
\text { ITCH, API5, ELMO2 }\end{array}$ & $\begin{array}{l}\text { ATM, PTEN, CCL5, LEF1, } \\
\text { BCL11B, TFAP2B, CUL3, } \\
\text { TOPORS, ERBB4, ANGPT1, } \\
\text { IL18, TCF7, CDH5, } \\
\text { E2F3, WNT4, SMAD4, } \\
\text { SOX17, TCF19, SKAP2, } \\
\text { CDK6, WANT7B }\end{array}$ & $\begin{array}{l}\text { LEF1, } \\
\text { BCL11B, } \\
\text { TFAP2B }\end{array}$ \\
\hline hsa-miR-450a-5p & ERCC5, PRELP & $\begin{array}{l}\text { ERCC5, STK4, MCF2, PRF1, } \\
\text { EGFR, ISL1, BMF }\end{array}$ & $\begin{array}{l}\text { STK4, TES, OGN, } \\
\text { EGFR, ISL1 }\end{array}$ & - \\
\hline
\end{tabular}

NHDFs, normal human dermal fibroblasts; miRNAs, microRNAs; $\mathrm{H}_{2} \mathrm{O}_{2}$, hydrogen dioxide.

damage in normal fibroblasts $(20,21)$. Although oridonin induces apoptosis with rapid ROS generation in cancer cells, the effects of oridonin on ROS synthesis vary in a dose-dependent manner. Relatively high doses of oridonin $(\geq 10 \mu \mathrm{M})$ induce a high level of ROS and apoptosis in cancer cells, whereas relatively low doses reduce ROS induction and improve survival in normal cells (21). Even at concentrations that induce apoptosis in cancer cells, oridonin does not induce apoptosis in normal human fibroblasts (20). However, it is unknown how oridonin affects antioxidant-mediated cell survival, and which mechanisms are involved in antioxidative-stress activity in cells. In this study, we found that oridonin inhibits $\mathrm{H}_{2} \mathrm{O}_{2}$-mediated cell death by altering the expression levels of specific miRNAs and inducing intracellular ROS depletion. Moreover, using bioin- formatic analysis, we suggest that the up- and downregulated miRNAs are functionally related to several cellular processes, including anti-apoptosis and cell growth.

Oridonin belongs to the class of terpenoid compounds, also known as isoprenoids, which is one of the most extensive and diverse classes of naturally occurring organic compounds (31). These terpenoids are well known as plant antioxidants (32). We determined that oridonin is a functional antioxidant reagent. As anticipated, although other terpenoid compounds (33-35), such as curcuminoids, cannabinoids and resveratrols, have direct free radical scavenging activity in vitro, we confirmed, using the cell-free DPPH assay, that oridonin has no free radical-scavenging activity. However, we confirmed, using a cell-based DCF-DA assay, that the levels 
Table III. Predicted targets of miRNAs downregulated in response to oridonin in $\mathrm{H}_{2} \mathrm{O}_{2}$-treated NHDFs.

\begin{tabular}{|c|c|c|c|c|}
\hline \multirow[b]{2}{*}{ miRNA } & \multicolumn{4}{|c|}{ Target genes and functions } \\
\hline & Aging & Apoptosis & Cell proliferation & $\begin{array}{c}\text { Skin } \\
\text { development }\end{array}$ \\
\hline hsa-miR-188-5p & $\begin{array}{l}\text { IL6, PML, } \\
\text { NEK6 }\end{array}$ & $\begin{array}{l}\text { IL6, PML, NEK6, VAV3 } \\
\text { PDCD10, AIf1, FGFR1, HDAC1 } \\
\text { HGF, INSL3, SOX4, ADAM17, } \\
\text { CD28, ARHGEF9, MAP2K4, TIAM1, } \\
\text { PIK3R1, ESR1, LTBR, API5 }\end{array}$ & $\begin{array}{l}\text { IL6, PML, VAV3, PDCD10, } \\
\text { AIf1, FGFR1, HDAC1, HGF, } \\
\text { INSL3, SOX4, ADAM17, CD28, } \\
\text { CDH5, DLG3, DPP4, SUZ12, } \\
\text { GLUL, ANG, PKD2, NEUROD4, } \\
\text { WNT2, CDC73, PIK3R1, KRAS, } \\
\text { API5, ID4 }\end{array}$ & DHCR24 \\
\hline hsa-miR-572 & $\begin{array}{l}\text { NOX4, FZR1, } \\
\text { CDH1 }\end{array}$ & $\begin{array}{l}\text { CDH13, NFKB1, BFAR, } \\
\text { UACA, ACTN2, CDH1 }\end{array}$ & $\begin{array}{l}\text { NOX4, CDH13, CTH, } \\
\text { CD164, CCNB1, FZR1 }\end{array}$ & - \\
\hline hsa-miR-630 & $\begin{array}{l}\text { SOD2, HMGCR, } \\
\text { MME, CANX, } \\
\text { TP63, SERPINA7, } \\
\text { CACBP, ZNF354A, } \\
\text { ATP5G3 }\end{array}$ & $\begin{array}{l}\text { SOD2, FOXO1, KDR, PAK7, } \\
\text { RHOB, MEF2D, RAC1, RAG1, } \\
\text { XRCC5, TP63, MPO, PAX3, SMNDC1, } \\
\text { CYLD, PSME4, DOCK1, TP53INP1, } \\
\text { CXCL13, COL4A3, IL7, TLR4, } \\
\text { YAP1, MAP3K1, BCL2L2, NOTCH2 }\end{array}$ & $\begin{array}{l}\text { SOD2, EPHA2, FOXO1, IL7, } \\
\text { GJA1, CYR61, KDR, PAWR, } \\
\text { TBX18, SAV1, TP63, CD80, } \\
\text { PAX3, GINS1, FRS2, TOB2, } \\
\text { PAK7, RASGRF1, NOTCH2, BMPR2, } \\
\text { FABP7, CDC14A, E3F3, PELI1, } \\
\text { FXD6, KLF5, PID1, CDC7, } \\
\text { COL4A3, TLR4, YAP1, STK4 }\end{array}$ & TP63 \\
\hline hsa-miR-638 & $\begin{array}{l}\text { MAPK14, } \\
\text { HMGA1, }\end{array}$ & $\begin{array}{l}\text { MAPK14, NKX2-5, ADD1, } \\
\text { HSP90B1,CFLAR, ATG5, } \\
\text { USP47, TRIM2, XAF1, } \\
\text { ETS1, CIDEB, SAP30BP }\end{array}$ & $\begin{array}{l}\text { NKX2-5, HEY2, IFNG, LIF, } \\
\text { CDK2, TRAF5, OGN, CTF1, } \\
\text { VEFGA, MFGE8, PBRM1, NR4A3, } \\
\text { LIFR, IL11, NPPC, MCC, } \\
\text { CD47, SOX2, TGM2, } \\
\text { ACHE, GPC4 }\end{array}$ & TFAP2B \\
\hline hsa-miR-940 & $\begin{array}{l}\text { SIRT1, IL1B, } \\
\text { TBX3, TP53, } \\
\text { TGFBR1, CNR1, } \\
\text { ATM, CASP7, } \\
\text { MET, SHC1, } \\
\text { PTEN, SMC5, } \\
\text { JUN, SERP1 }\end{array}$ & $\begin{array}{l}\text { SIRT1, IL1B, TBX3, TGFBR1, } \\
\text { CNR1, APC, ERBB4, RHOA, } \\
\text { MDM2, PAK1, NOD2, SOX9, } \\
\text { IRS2, CD24, NOD1, RASSF6, } \\
\text { MAP2K6, PCBP4, TAOK1, RAD21, } \\
\text { MAP3K7, LITAF, TP53, BIRC3, } \\
\text { PTEN, ATM, NOTCH1, JUN }\end{array}$ & $\begin{array}{l}\text { SIRT1, IL1B, CRIP2, TBX3, } \\
\text { TGFBR1, NOTCH3, PAK1, } \\
\text { CNR1, APC, RHOA, MDM2, } \\
\text { ERBB4, NOD2, SOX9, IRS2, } \\
\text { CD24, PRDM4, MAB21L1, SGK2, } \\
\text { JAG1, KIF2C, DAB2, EGR1, } \\
\text { FGFR4, NFIB, ROR2, RAC2, } \\
\text { USP28, EVI5, XIAP, IGF1R, } \\
\text { TP53, ARIH2, PTEN, ATM, } \\
\text { PBX1, MAGI , JUN, } \\
\text { NUMB, FOXO4, NANOG }\end{array}$ & $\begin{array}{l}\text { COL5A3, } \\
\text { SUFU, } \\
\text { CTNNB1, } \\
\text { APC, } \\
\text { JUP }\end{array}$ \\
\hline hsa-miR-1234-3p & $\begin{array}{l}\text { TOP2A, FURIN, } \\
\text { LOXL2 }\end{array}$ & $\begin{array}{l}\text { TOP2A, BIRC5, BDNF, TCF7, } \\
\text { FADD, AKT1S1, TERT, MED1, } \\
\text { NR2E1, DSG1, BCL2 }\end{array}$ & $\begin{array}{l}\text { FURIN, TFAP2A, BIRC5, BDNF, } \\
\text { TCF7, CDKN1C, ELN, GATA2, } \\
\text { ATF3, IRAK4, WNT4, PLAG1, } \\
\text { GFAP, BCL2, GDF2, EGFR, } \\
\text { HOXA3, PRKX, MED1 }\end{array}$ & TFAP2A \\
\hline hsa-miR-1238-3p & $\begin{array}{l}\text { SMC6, ADM, } \\
\text { RTN4, LRP2 }\end{array}$ & $\begin{array}{l}\text { NGFR, PRAME, HDAC2, } \\
\text { BID, PROK2, WNT5A, PSMA8, } \\
\text { ADNP, ABR, ARF6, ROBO2, } \\
\text { PINK1, GCM2, TP53I3 }\end{array}$ & $\begin{array}{l}\text { NGFR, PRAME, HDAC2, PROK2, } \\
\text { WNT5A, CREB3, IGFBP5, IRS1, } \\
\text { MMP14, PTN, VASH2, FGF18, } \\
\text { CER1, BID, DNAJA2, ADAMTS1 }\end{array}$ & $\begin{array}{l}\text { COL5A2, } \\
\text { ITGA2 }\end{array}$ \\
\hline hsa-miR-1268a & $\begin{array}{l}\text { TERF2, DBH, } \\
\text { CDKN2A }\end{array}$ & $\begin{array}{l}\text { MAPK1, ADAM8, CARD8, } \\
\text { PAX8, EFNB1, CDKN2A }\end{array}$ & $\begin{array}{l}\text { MAPK1, EGR4, ESRRB, } \\
\text { TGFB1I1, GATA4, DBH }\end{array}$ & TGM3 \\
\hline
\end{tabular}

NHDFs, normal human dermal fibroblasts; miRNAs, microRNAs; $\mathrm{H}_{2} \mathrm{O}_{2}$, hydrogen dioxide. The results for the other miRNAs were excluded from this analysis. 
of intracellular ROS are indeed markedly reduced by oridonin treatment, suggesting that oridonin may regulate intracellular antioxidant mechanisms rather than directly scavenge free radicals.

Anti-cell-death functions have been demonstrated to be important in reducing oxidative stress-mediated cell death. In the present study, we examined the anti-cell-death effects of oridonin on oxidative stress, specifically those induced by $\mathrm{H}_{2} \mathrm{O}_{2} . \mathrm{H}_{2} \mathrm{O}_{2}$-mediated oxidative stress can induce cell death by various intracellular mechanisms, such as DNA breaks, protein oxidation, mitochondrial failure, impairment of energy metabolism, cell cycle arrest and apoptosis (1). Using PI staining and flow cytometric analysis, the NHDFs treated with $\mathrm{H}_{2} \mathrm{O}_{2}$ showed an increased sub-G1 population, representing apoptotic cells, whereas the oridonin-pre-treated cells showed a marked resistance to $\mathrm{H}_{2} \mathrm{O}_{2}$-mediated cell death. Therefore, we concluded that the oridonin-mediated antioxidative-stress activity is due to its anti-apoptotic effects, not its free radicalscavenging activity.

Several studies have demonstrated that $\mathrm{H}_{2} \mathrm{O}_{2}$ alters the miRNA expression profiles in a cell type-dependent manner. miR-135b and miR-708 have been shown to be highly upregulated by $\mathrm{H}_{2} \mathrm{O}_{2}$ treatment in primary hippocampal neuronal cells (36). In addition, miR-27a* and miR-27b* were notably downregulated in $\mathrm{H}_{2} \mathrm{O}_{2}$-treated RAW 264.7 mouse macrophages (37). miR-30b and miR-30d have been shown to be significantly upregulated in $\mathrm{H}_{2} \mathrm{O}_{2}$-treated ARPE-19 human retinal pigment epithelial cells (38), and the expression levels of these miRNAs can also be altered by treatment with the antioxidant compound, curcumin. These reports suggest that miRNAs that are modulated in response to $\mathrm{H}_{2} \mathrm{O}_{2}$ and antioxidants differ depending on cell and antioxidant type. In this study, we identified putative antioxidant miRNAs regulated by oridonin, specifically miR-1238-3p and miR-191-3p in NHDFs. Of note, miR-1238-3p was downregulated to the greatest extent ( $>7$-fold) by oridonin, and SMC6 had the highest target score among its target genes. SMC6 is a core member of the SMC5-6DNA repair complex, and it has been reported to function as a key component of the DNA damage response (39). Of the types of cellular damage induced by oxidative stress, ROS can induce oxidative damage of DNA, including strand breaks and base and nucleotide modifications (40). Although the cellular effects and target genes of miR-1238-3p have not been investigated, further studies on miR-1238-3p and SMC6 may aid in the understanding of the cellular response to oridonin. miR-191, which is downregulated in follicular adenoma, was recently shown to inhibit cell growth and migration by targeting CDK6, a serine-threonine kinase involved in the control of cell cycle progression (41). Although the biological functions of miR-1238 and miR-191 are largely unknown, these miRNAs may be the specific targets for antioxidative stress in NHDFs.

In conclusion, in this study, to the best of our knowledge, we evaluated for the first time the effects of oridonin on the expression levels of miRNAs in NHDFs in the presence of oxidative stress. The cellular mechanisms underlying the antioxidative effects of oridonin on $\mathrm{H}_{2} \mathrm{O}_{2}$-mediated damage in cells remain unknown; however, our study provides substantial evidence of the role of oridonin as a chemoprotective agent against $\mathrm{H}_{2} \mathrm{O}_{2}$-mediated damage in HDFs. Although further studies are required to verify the predicted miRNA targets identified in this study, our results suggest that the characterization of changes in expression of oridonin-specific miRNAs may provide a useful approach to understanding cellular responses to oridonin in $\mathrm{H}_{2} \mathrm{O}_{2}$-induced NHDF damage.

\section{Acknowledgements}

The authors thank all members of the research group for their support and advice regarding this study. This study was supported by the KU Research Professor Program of Konkuk University and a grant from the Ministry of Science, ICT and Future Planning (Grant 20110028646) of the Republic of Korea.

\section{References}

1. Cerella C, Coppola S, Maresca V, De Nicola M, Radogna F and Ghibelli L: Multiple mechanisms for hydrogen peroxide-induced apoptosis. Ann N Y Acad Sci 1171: 559-563, 2009.

2. Knight JA: Reactive oxygen species and the neurodegenerative disorders. Ann Clin Lab Sci 27: 11-25, 1997.

3. Abe J and Berk BC: Reactive oxygen species as mediators of signal transduction in cardiovascular disease. Trends Cardiovasc Med 8: 59-64, 1998.

4. Boh EE: Role of reactive oxygen species in dermatologic diseases. Clin Dermatol 14: 343-352, 1996.

5. Feng B, Ma LJ, Yao JJ, Fang Y, Mei YA and Wei SM: Protective effect of oat bran extracts on human dermal fibroblast injury induced by hydrogen peroxide. J Zhejiang Univ Sci B 14: 97-105, 2013.

6. Lorenz P, Roychowdhury S, Engelmann M, Wolf G and Horn TF: Oxyresveratrol and resveratrol are potent antioxidants and free radical scavengers: effect on nitrosative and oxidative stress derived from microglial cells. Nitric Oxide 9: 64-76, 2003.

7. Lagouge M, Argmann C, Gerhart-Hines Z, et al: Resveratrol improves mitochondrial function and protects against metabolic disease by activating SIRT1 and PGC-1alpha. Cell 127: 1109-1122, 2006.

8. Becatti M, Prignano F, Fiorillo C, et al: The involvement of Smac/DIABLO, p53, NF-kB, and MAPK pathways in apoptosis of keratinocytes from perilesional vitiligo skin: Protective effects of curcumin and capsaicin. Antioxid Redox Signal 13: 1309-1321, 2010.

9. Pellinen RI, Korhonen MS, Tauriainen AA, Palva ET and Kangasjarvi J: Hydrogen peroxide activates cell death and defense gene expression in birch. Plant Physiol 130: 549-560, 2002.

10. Wei Q, Huang H, Yang L, et al: Hydrogen peroxide induces adaptive response and differential gene expression in human embryo lung fibroblast cells. Environ Toxicol: Apr 4, 2012 (Epub ahead of print)

11. Vandenbroucke K, Robbens S, Vandepoele K, Inze D, Van de Peer Y and Van Breusegem F: Hydrogen peroxide-induced gene expression across kingdoms: a comparative analysis. Mol Biol Evol 25: 507-516, 2008.

12. Tian W and Chen SY: Recent advances in the molecular basis of anti-neoplastic mechanisms of oridonin. Chin J Integr Med 19: 315-320, 2013.

13. Wang H, Ye Y, Chui JH, et al: Oridonin induces G2/M cell cycle arrest and apoptosis through MAPK and p53 signaling pathways in HepG2 cells. Oncol Rep 24: 647-651, 2010.

14. Li CY, Wang EQ, Cheng Y and Bao JK: Oridonin: An active diterpenoid targeting cell cycle arrest, apoptotic and autophagic pathways for cancer therapeutics. Int J Biochem Cell Biol 43: 701-704, 2011.

15. Wang S, Zhong Z, Wan J, et al: Oridonin induces apoptosis, inhibits migration and invasion on highly-metastatic human breast cancer cells. Am J Chin Med 41: 177-196, 2013.

16. Gao FH, Liu F, Wei W, et al: Oridonin induces apoptosis and senescence by increasing hydrogen peroxide and glutathione depletion in colorectal cancer cells. Int J Mol Med 29: 649-655, 2012.

17. Zhang YH, Wu YL, Tashiro S, Onodera S and Ikejima T: Reactive oxygen species contribute to oridonin-induced apoptosis and autophagy in human cervical carcinoma HeLa cells. Acta Pharmacol Sin 32: 1266-1275, 2011. 
18. Yu Y, Fan SM, Song JK, Tashiro S, Onodera S and Ikejima T: Hydroxyl radical $(\cdot \mathrm{OH})$ played a pivotal role in oridonin-induced apoptosis and autophagy in human epidermoid carcinoma A431 cells. Biol Pharm Bull 35: 2148-2159, 2012.

19. Huang J, Wu L, Tashiro S, Onodera S and Ikejima T: Reactive oxygen species mediate oridonin-induced HepG2 apoptosis through p53, MAPK, and mitochondrial signaling pathways. J Pharmacol Sci 107: 370-379, 2008.

20. Chen S, Gao J, Halicka HD, Huang X, Traganos F and Darzynkiewicz Z: The cytostatic and cytotoxic effects of oridonin (Rubescenin), a diterpenoid from Rabdosia rubescens, on tumor cells of different lineage. Int J Oncol 26: 579-588, 2005.

21. Du Y, Villeneuve NF, Wang XJ, et al: Oridonin confers protection against arsenic-induced toxicity through activation of the Nrf2-mediated defensive response. Environ Health Perspect 116: 1154-1161, 2008.

22. Cheng AM, Byrom MW, Shelton J and Ford LP: Antisense inhibition of human miRNAs and indications for an involvement of miRNA in cell growth and apoptosis. Nucleic Acids Res 33: 1290-1297, 2005.

23. An IS, An S, Kang SM, et al: Titrated extract of Centella asiatica provides a UVB protective effect by altering microRNA expression profiles in human dermal fibroblasts. Int J Mol Med 30 1194-1202, 2012

24. Mancini M, Saintigny G, Mahe C, Annicchiarico-Petruzzelli M, Melino G and Candi E: MicroRNA-152 and -181a participate in human dermal fibroblasts senescence acting on cell adhesion and remodeling of the extra-cellular matrix. Aging (Albany NY) 4 843-853, 2012.

25. Sing T, Jinnin M, Yamane K, et al: microRNA-92a expression in the sera and dermal fibroblasts increases in patients with scleroderma. Rheumatology (Oxford) 51: 1550-1556, 2012.

26. Ishiyama $M$, Tominaga $H$, Shiga $M$, Sasamoto $K$, Ohkura $Y$ and Ueno K: A combined assay of cell viability and in vitro cytotoxicity with a highly water-soluble tetrazolium salt, neutral red and crystal violet. Biol Pharm Bull 19: 1518-1520, 1996.

27. Bae S, Jeong HJ, Cha HJ, et al: The hypoxia-mimetic agent cobalt chloride induces cell cycle arrest and alters gene expression in U266 multiple myeloma cells. Int J Mol Med 30: 1180-1186, 2012.

28. Kim YJ, Cha HJ, Nam KH, Yoon Y, Lee H and An S: Centella asiatica extracts modulate hydrogen peroxide-induced senescence in human dermal fibroblasts. Exp Dermatol 20 998-1003,2011.
29. Pillai RS, Bhattacharyya SN and Filipowicz W: Repression of protein synthesis by miRNAs: how many mechanisms? Trends Cell Biol 17: 118-126, 2007.

30. Elmore S: Apoptosis: a review of programmed cell death. Toxicol Pathol 35: 495-516, 2007.

31. Gonzalez-Burgos E and Gomez-Serranillos MP: Terpene compounds in nature: a review of their potential antioxidant activity. Curr Med Chem 19: 5319-5341, 2012.

32. Grassmann J: Terpenoids as plant antioxidants. Vitam Horm 72: 505-535, 2005.

33. Pozharitskaya ON, Ivanova SA, Shikov AN and Makarov VG: Separation and free radical-scavenging activity of major curcuminoids of Curcuma longa using HPTLC-DPPH method. Phytochem Anal 19: 236-243, 2008

34. Moldzio R, Pacher T, Krewenka C, et al: Effects of cannabinoids $\Delta(9)$-tetrahydrocannabinol, $\Delta(9)$-tetrahydrocannabinolic acid and cannabidiol in $\mathrm{MPP}^{+}$affected murine mesencephalic cultures. Phytomedicine 19: 819-824, 2012.

35. Khanduja KL and Bhardwaj A: Stable free radical scavenging and antiperoxidative properties of resveratrol compared in vitro with some other bioflavonoids. Indian J Biochem Biophys 40: 416-422, 2003.

36. Xu S, Zhang R, Niu J, et al: oxidative stress mediated-alterations of the microRNA expression profile in mouse hippocampal neurons. Int J Mol Sci 13: 16945-16960, 2012.

37. Thulasingam S, Massilamany C, Gangaplara A, et al: miR-27b*, an oxidative stress-responsive microRNA modulates nuclear factor-kB pathway in RAW 264.7 cells. Mol Cell Biochem 352. 181-188, 2011.

38. Haque R, Chun E, Howell JC, Sengupta T, Chen D and Kim H: MicroRNA-30b-mediated regulation of catalase expression in human ARPE-19 cells. PLoS One 7: e42542, 2012.

39. Roy MA and D'Amours D: DNA-binding properties of Smc6, a core component of the Smc5-6 DNA repair complex. Biochem Biophys Res Commun 416: 80-85, 2011.

40. Bennett MR: Reactive oxygen species and death: oxidative DNA damage in atherosclerosis. Circ Res 88: 648-650, 2001.

41. Colamaio M, Borbone E, Russo L, et al: miR-191 down-regulation plays a role in thyroid follicular tumors through CDK6 targeting. J Clin Endocrinol Metab 96: E1915-E1924, 2011 